\title{
Effects of dietary turmeric supplementation on plasma lipoproteins, meat quality and fatty acid composition in broilers
}

\author{
M. Daneshyar ${ }^{1,2}$, M. Alizadeh Ghandkanlo ${ }^{1}$, F. Sabzi Bayeghra ${ }^{1}$, F. Farhangpajhoh ${ }^{3}$ \\ \& M. Aghaei ${ }^{4}$ \\ ${ }^{1}$ Department of Animal Science, Faculty of Agriculture, Urmia University, Urmia, Iran \\ ${ }^{2}$ Department of Medicinal and Industrial Plants, Institute of Biotechnology, ${ }^{3}$ Central Veterinary Laboratory, \\ Faculty of Veterinary, Urmia University, Iran, ${ }^{4}$ Department of Horticulture, Urmia University, Iran
}

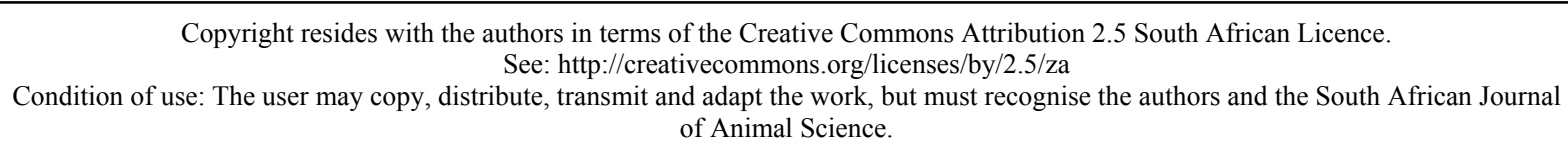

Copyright resides with the authors in terms of the Creative Commons Attribution 2.5 South African Licence.

See: http://creativecommons.org/licenses/by/2.5/za

Condition of use: The user may copy, distribute, transmit and adapt the work, but must recognise the authors and the South African Journal of Animal Science.

\begin{abstract}
An experiment with 200 day-old male broiler chickens was conducted to investigate the effect of the dietary supplementation of turmeric rhizome powder (TRP) on plasma lipoprotein concentrations, and the meat quality and fatty acid composition of the thigh muscle of the broilers. The four treatments were $0 \%$ (F.TRP), $0.25 \%$ (L.TRP), $0.50 \%$ (M.TRP) and $0.75 \%$ (H.TRP) TRP in the diets. The $\mathrm{pH}$ and the fat, protein, dry matter and ash concentrations of thigh meat did not show significant differences between treatments. There were no significant differences between treatments in the concentrations of plasma triglyceride, total cholesterol and very low-density lipoprotein-cholesterol (VLDL-c) at three weeks, and for plasma lowdensity lipoprotein (LDL-c) at three and six weeks of age. At week 6, the M.TRP- and H.TRP-fed birds showed lower plasma triglyceride and VLDL-c concentrations than the birds in the other treatments. At weeks 3 and 6 the concentration of plasma high-density lipoprotein-cholesterol (HDL-c) of the M.TRP- and H.TRP-fed birds was significantly higher than that of the F.TRP-fed birds. At week 6, the H.TRP-fed birds had significantly lower concentrations of saturated fatty acids (SFA) in the thigh and total cholesterol in the plasma than the F.TRP-fed birds and the other birds. Moreover, a significantly higher thigh vaccenic acid concentration was indicated for the H.TRP-fed birds compared with the L.TRP- and F.TRP-fed birds. In orthogonal comparisons, TRP consumption reduced the concentration of plasma triglycerides and dry matter of thigh meat, as well as triglyceride, palmitic acid and total SFA concentrations, but increased the thigh meat protein and plasma HDL-c concentrations significantly, compared with the control. In conclusion, supplementation of TRP in broiler chickens diets can decrease the concentrations of SFAs and triglycerides in thigh meat and improve the meat quality as a result.
\end{abstract}

Keywords: Turmeric rhizome powder, thigh meat, proximate analysis, cholesterol, triglycerides Corresponding author: m.daneshyar@urmia.ac.ir

\section{Introduction}

Dietary levels of cholesterol (Hayes, 1995) and fatty acid profiles in lipid fractions (Blanch \& Grashorn, 1996) are associated with the development of atherosclerosis and coronary artery diseases in humans. Dietary saturated fatty acids (SFA) increase the plasma cholesterol and low-density lipoproteincholesterol (LDL-c) concentrations, whereas polyunsaturated fatty acids (PUFA) reduce the plasma cholesterol and LDL-c concentrations in humans (Aletor et al., 2003). Chicken meat is healthier than other meat sources for human consumption because of its low cholesterol and fat content (Ponte et al., 2004), but several studies have been used to decrease the SFA and cholesterol content of broiler meat.

Dietary inclusion of PUFA (especially n-3 fatty acids) sources such as linseed oil (Crespo \& EsteveGarcia, 2002; Bou et al., 2005) and fish oil (Lopez-Ferrer et al., 1999; Bou et al., 2004) in broiler diets have been used to manipulate the fatty acid composition and decrease the detrimental ingredients in meat. Recently, researches have focused on the beneficial effects of phytogenic substances in broiler chickens. Cholesterol and lipoprotein decreasing effects of alfalfa (Ponte et al., 2004), thyme (Bolukbasi et al., 2006) 
and garlic (Konjufca et al., 1997; Habibian Dehkordi et al., 2010) have been shown in broilers. Phenolic compounds are phytogenic substances that have hypocholesterolemic effects (Ikeda et al., 1992; Hirose et al., 1991). For example, phenolic compounds in red wine have been reported to lower the incidence of cardiovascular diseases in humans in France (Staley \& Mazier, 1999). The mechanisms behind the hypocholesterolemic and other beneficial effects of dietary phenolic compounds have not been fully elucidated (Kamal-Eldin, 2000).

Curcuma longa is a medical plant that belongs to the ginger (Zingiberaceae) family and is a major source of phenolic compounds (curcuminoids). It is a perennial plant with a short stem and large oblong leaves, and it bears ovate, pyriform or oblong rhizomes, which are often branched and brownish-yellow in colour. Turmeric is the rhizome of Curcuma longa L. and is used as a food spice, and a preservative and colouring agent in China and South East Asia (Ammon et al., 1992; Mishra et al., 2009). In recent years, traditional Indian medicine has been using turmeric powder for the treatment of biliary disorders, anorexia, coryza, cough, diabetic wounds, hepatic disorders, rheumatism and sinusitis (Ammon et al., 1992; Mishra et al., 2009). Curcuminoids, such as curcumin, demethoxycurcumin and bisdemethoxycurcumin, are yellowish turmeric pigments and have antioxidative, anticarcinogenic, anti-inflammatory, antihepatotoxic and hypocholesterolemic activities (Nishiyama et al., 2005). In addition to the curcuminoids, compounds such as $\gamma$-terpinene, ascorbic acid, beta-carotene, betasitosterol, caffeic acid, campestrol, camphene, dehydrocurdione, eugenol, p-coumaric acid, protocatechuic acid, stigmasterol, syringic acid, turmerin, turmeronola, turmeronol-b and vanillic acid possess antioxidant capabilities (Duke, 2004).

Curcumin is the main phenolic compound of TRP that has an antioxidant effect. It inhibits lipid peroxidation, scavenges the superoxide anion and hydroxyl radicals (Ruby et al., 1995) and enhances the activities of detoxifying enzymes such as glutathione-S-transferase (Piper et al., 1998). Instead of antioxidant effects, curcumin has a hypocholesterolemic effect. It can reduce the concentrations of plasma low-density lipoproteins and very low-density lipoproteins and liver total cholesterol (Kamal-Eldin et al., 2000). Up to a $0.75 \%$ dietary inclusion of TRP has increased the concentration of high-density lipoprotein-cholesterol (HDL-c) and decreased the low-density lipoproteins of plasma in broiler chickens (Emadi et al., 2007). Increasing the dietary TRP to $0.2 \%$ has decreased serum triglyceride, total cholesterol and LDL-c concentrations in laying hens (Kermanshahi \& Riasi, 2006). Both $0.1 \%$ and $0.5 \%$ curcumin in the diet have reduced the cholesterol in the liver and serum of rats (Rao et al., 1970). Although the plasma cholesterol lowering effects of TRP have been shown in broiler chickens, no study is available on its effect on the meat quality of broiler chickens. Therefore, the current experiment was designed to study the effects of dietary TRP supplementation on the triglyceride, proximate analyses and fatty acid composition of the thigh meat of chickens.

\section{Material and Methods}

In this experiment, 200 day-old male broiler chickens (Ross 308) were obtained and allocated randomly to 20 pens $\left(1 \mathrm{x}^{\circ} \mathrm{m}^{2}, 10\right.$ birds per pen). Continuous light was used in the house. The birds were reared at $32{ }^{\circ} \mathrm{C}$ during the first two days, and then the house temperature was reduced by $2{ }^{\circ} \mathrm{C}$ per week up to week 5, when the temperature was kept at $22 \pm 1{ }^{\circ} \mathrm{C}$ until the end of the experiment (Daneshyar et al., 2007; 2009). All the birds received a mash broiler starter (from day 1 to day 21 of age) and a grower (from day 22 to day 42 of age) diet (Table 1), but they received different treatment levels of TRP in the diet: 0\% (F.TRP), $0.25 \%$ (L.TRP), $0.50 \%$ (M.TRP) and $0.75 \%$ (H.TRP) TRP. The levels of $0 \%, 0.25 \%, 0.50 \%$ and $0.75 \%$ TRP replaced wheat bran in the diets, respectively. Fresh Indian turmeric rhizome (having $15.48 \mathrm{mg}$ total phenolic compounds/g) was ground and mixed with the diets. At week 3, one chicken from each replicate pen (five per treatment) was selected randomly and marked for blood collection. Wing-vein blood samples were obtained after three hours of starvation at weeks 3 and 6 . The blood samples were immediately transferred to anticoagulant tubes (sodium citrate, 3.6\%). Then plasma was separated by centrifuge ( $3500 \mathrm{rpm}$ for $15 \mathrm{~min}$ ) and stored at $-20{ }^{\circ} \mathrm{C}$ for later analysis. At the end of the experiment (week 6), five chickens from each replicate (pen) were randomly selected and slaughtered. Three pieces of the meat of the left thigh were removed and used for determination of $\mathrm{pH}$, proximate analyses, fatty acid composition and triglyceride content. The experimental protocol was reviewed and approved by the Animal Care Committee of the University of Urmia, Iran. The standard extraction method of Seevers \& Daly (1970) was used for estimation of total phenols. One gram turmeric rhizome was crushed in $10 \mathrm{~mL}$ of $80 \%$ methanol in a pestle and mortar. The extract was filtered and centrifuged at $1000 \mathrm{x} g$ for $5 \mathrm{~min}$ and the supernatant was collected and used for 
the determination of phenolic compounds, using the colorimetric method at absorbance of $720 \mathrm{~nm}$ with $20 \%$ $\mathrm{Na}_{2} \mathrm{CO}_{3}$ and in Folin-Ciocalteau reagent. Gallic acid was used as the standard.

Table 1 Ingredient and nutrient composition of the experimental diets

\begin{tabular}{|c|c|c|}
\hline & $\operatorname{Starter}(0-21 d)$ & Grower $(22-42 d)$ \\
\hline \multicolumn{3}{|l|}{ Ingredients $(\mathrm{g} / \mathrm{kg})$} \\
\hline Maize & 492.8 & 616.2 \\
\hline Soybean meal (440 g protein $/ \mathrm{kg}$ ) & 337.7 & 244.0 \\
\hline Fish meal & 67.2 & 67.9 \\
\hline Soybean Oil & 24.0 & - \\
\hline Fat powder & 50.0 & 50.0 \\
\hline Oyster shell & 2.4 & 3.3 \\
\hline Dicalcium phosphate & 8.5 & 3.7 \\
\hline Vitamin and mineral premix ${ }^{1}$ & 5.0 & 5.0 \\
\hline Salt & 4.7 & 2.3 \\
\hline DL-methionine & 1.1 & 0.1 \\
\hline Wheat bran & 7.5 & 7.5 \\
\hline Total & 1000 & 1000 \\
\hline \multicolumn{3}{|l|}{ Calculated analysis } \\
\hline Metabolizable energy $(\mathrm{MJ} / \mathrm{kg})$ & 13.4 & 13.4 \\
\hline Crude protein $(\mathrm{g} / \mathrm{kg})$ & 230 & 200 \\
\hline Calcium $(\mathrm{g} / \mathrm{kg})$ & 10 & 9 \\
\hline Available phosphorus $(\mathrm{g} / \mathrm{kg})$ & 4.5 & 3.5 \\
\hline Sodium $(\mathrm{g} / \mathrm{kg})$ & 2.0 & 1.5 \\
\hline Arginine $(\mathrm{g} / \mathrm{kg})$ & 15.2 & 12.7 \\
\hline Methionine + Cystine $(\mathrm{g} / \mathrm{kg})$ & 9.0 & 7.2 \\
\hline Lysine $(\mathrm{g} / \mathrm{kg})$ & 13.8 & 11.7 \\
\hline Tryptophan (g/kg) & 3.3 & 2.7 \\
\hline
\end{tabular}

\footnotetext{
${ }^{1}$ Supplied per kilogram of diet: 9000 IU retinol; 20000 IU cholecaciferol; 360 IU tocopherol; $15 \mathrm{mg}$ cyanocobalamin; $66 \mathrm{mg}$ riboflavin; $98 \mathrm{mg}$ pantothenate; $29 \mathrm{mg}$ niacin; $250 \mathrm{mg}$, choline; $100 \mu \mathrm{g}$ biotin; $17 \mathrm{mg}$ thiamine; $84 \mathrm{mg}$ zinc; $99 \mathrm{mg}$ manganese; $10 \mathrm{mg}$ copper; $20 \mu \mathrm{g}$ selenium; $99 \mu \mathrm{g}$ iodine; $50 \mathrm{mg}$ iron.
}

Determination of dry matter (DM), crude protein (CP), ether extract (EE) and ash contents was performed according to the AOAC methods (AOAC, 1998). The $\mathrm{pH}$ of thigh meat was measured using a digital pH meter (TitroLine Easy, Schott Instruments, Mainz, Germany) after homogenization in distilled water.

Plasma samples were thawed and the concentrations of total cholesterol, HDL-c, LDL-c, VLDL-c and triglycerides were determined using a spectrophotometer (Unico-2400, Unico-Japan Co. Ltd.) and commercial enzymatic kits (Pars Azmoon Co., Tehran-Iran).

Total lipids were extracted by the method of Folch et al. (1957) and measured gravimetrically. The formation of fatty acid methyl esters (FAME) was carried out according to the procedure described by Desvilettes et al. (1994). The sample was saponified with methanolic sodium hydroxide, and the fatty acids were esterified with methanolic sulphuric acid. FAME were analyzed with a 6890 N GC-FID (Agilent Technologies, Wilmington, DE, USA) fitted with a J\&W DB-Wax capillary column $(30 \mathrm{~m}, 0.25 \mathrm{~mm}$ i.d., $0.25 \mathrm{~mm}$ film thickness), a split-splitless injector with Agilent tapered liner (4 mm i.d.) and a flame ionization detector. The initial column temperature was maintained at $100{ }^{\circ} \mathrm{C}$ for $1 \mathrm{~min}$ and then raised at 25 
${ }^{\circ} \mathrm{C} / \mathrm{min}$ to $190{ }^{\circ} \mathrm{C}$ and held for $10 \mathrm{~min}$, and then raised to $220{ }^{\circ} \mathrm{C}$ and held for $5 \mathrm{~min}$. Nitrogen was used as carrier and makeup gas, at flow rates of 1.0 and $45 \mathrm{~mL} / \mathrm{min}$, respectively. The injector and detector temperatures were held at $250{ }^{\circ} \mathrm{C}$ and $260{ }^{\circ} \mathrm{C}$, respectively. ChemStation software was used for online data collection and processing. Individual FAME was identified by comparison with known standards (SigmaAldrich Corps, St Louis, MO, USA).

Thigh meat lipids were extracted by the modified method of Hara \& Radin (1978). Nine $\mathrm{mL}$ of extraction solution (hexane : isopropanol, $3: 2 \mathrm{v} / \mathrm{v}$ ) were added to $0.5 \mathrm{~g}$ of thigh meat and homogenized, using glass beads, for $8 \mathrm{~h}$ at room temperature. After homogenization, the organic phase was separated by centrifugation at $2000 \times g$ for $10 \mathrm{~min}$, dehydrated by saturated sodium sulphate and finally used for the triglyceride assay according to the method of Neri \& Frings (1973). The triglyceride concentration in the thigh meat was measured on a spectrophotometer (Unico-2400, Japan) at a wavelength of $410 \mathrm{~nm}$.

The data were analyzed based on a completely randomized design using the general linear model procedure of SAS (SAS, 2002). When treatment means were significant $(P \leq 0.05)$, the Duncan multiple range test was used to separate the means. Moreover, orthogonal contrasts were constructed to compare the mean response variables for turmeric fed birds with the control birds.

\section{Results}

No significant differences between the treatments were indicated at week 6 for $\mathrm{pH}$, concentrations of fat, dry matter and ash of the thigh meat (Table 2). A trend was observed in the protein level of the thigh meat $(P=0.056)$, but this difference was not significant. Furthermore, compared to the control diet, TRP consumption did not change the $\mathrm{pH}$, fat or ash content, but decreased the $\mathrm{DM}$ and triglyceride and increased the protein content of thigh meat $(P<0.05)$.

Table 2 The $\mathrm{pH}$, dry matter (DM), ether extract (EE), crude protein (CP), ash and triglyceride (TG) concentrations of thigh meat in broiler chickens receiving $0 \%$ (F.TRP), $0.25 \%$ (L.TRP), $0.50 \%$ (M.TRP) and $0.75 \%$ (H.TRP) turmeric rhizome powder through the diet

\begin{tabular}{lcccccc}
\hline Treatments $^{1}$ & $\mathrm{pH}$ & DM (\%) & EE (\%) & CP (\%) & Ash (\%) & TG (mg/g) \\
\hline F.TRP & 5.88 & 31.5 & 35.4 & 18.4 & 1.26 & $193.8^{\mathrm{a}}$ \\
L.TRP & 5.86 & 30.0 & 32.4 & 19.1 & 1.13 & $186.0^{\mathrm{a}}$ \\
M.TRP & 5.91 & 30.3 & 32.2 & 19.0 & 1.27 & $81.2^{\mathrm{b}}$ \\
H.TRP & 5.86 & 30.0 & 32.1 & 19.4 & 1.25 & $88.2^{\mathrm{b}}$ \\
SEM & 0.02 & 0.23 & 1.1 & 0.14 & 0.04 & 16.9 \\
$P$ Value & 0.85 & 0.08 & 0.69 & 0.056 & 0.72 & 0.008 \\
\hline TRP vs. control & & & & & & 0.07 \\
$\quad P$ value & 0.94 & 0.01 & 0.23 & 0.01 & 0.02 \\
\hline
\end{tabular}

\footnotetext{
${ }^{\mathrm{a}-\mathrm{b}}$ Mean values within the same column with different superscripts differ significantly $(P<0.05)$.
}

${ }^{1}$ The thigh meat of five chickens per treatment was used for these determinations.

The plasma lipoproteins and triglyceride concentrations are presented in Table 3. At week 3 no significant differences were observed in plasma triglyceride concentrations between the treatments, but at week 6 the birds on both the M.TRP and H.TRP diets had lower plasma triglyceride concentrations than those on L.TRP and F.TRP. There were no significant differences in total cholesterol concentration between the treatments at week 3. However, at week 6 the H.TRP-fed birds showed a lower total cholesterol concentration than the birds in the other treatments.

Plasma HDL-c concentration of the H.TRP- and M.TRP-fed birds was greater than that of the control birds, but no significant differences in the concentration of plasma HDL-c were observed between the L.TRP-fed birds and other treatments. There were no significant differences in plasma LDL-c concentration 
Table 3 Plasma triglyceride (TG), total cholesterol (TC), high-density lipoprotein-cholesterol (HDL-c), lowdensity lipoprotein-cholesterol (LDL-c) and very low-density lipoprotein-cholesterol (VLDL-c) in broiler chickens receiving $0 \%$ (F.TRP) or $0.25 \%$ (L.TRP), $0.50 \%$ (M.TRP) and $0.75 \%$ (H.TRP) turmeric rhizome powder through the diet

\begin{tabular}{ccccccccccc}
\hline \multirow{2}{*}{ Treatments $^{1}$} & \multicolumn{2}{c}{ TG (mg/dL) } & \multicolumn{2}{c}{ TC (mg/dL) } & \multicolumn{2}{c}{ HDL-c (mg/dL) } & \multicolumn{2}{c}{ LDL-c (mg/dL) } & \multicolumn{2}{c}{ VLDL-c (mg/dL) } \\
\cline { 2 - 12 } & Wk 3 & Wk 6 & Wk 3 & Wk 6 & Wk 3 & Wk 6 & Wk 3 & Wk 6 & Wk 3 & Wk 6 \\
\hline F.TRP & 38.0 & $39.3^{\mathrm{a}}$ & 86.3 & $87.6^{\mathrm{a}}$ & $40.3^{\mathrm{b}}$ & $37.1^{\mathrm{b}}$ & 30.1 & 33.7 & 7.6 & $7.4^{\mathrm{a}}$ \\
L.TRP & 36.8 & $42.1^{\mathrm{a}}$ & 74.2 & $87.8^{\mathrm{a}}$ & $38.6^{\mathrm{ab}}$ & $42.7^{\mathrm{ab}}$ & 33.0 & 34.2 & 7.4 & $8.4^{\mathrm{a}}$ \\
M.TRP & 36.5 & $25.0^{\mathrm{b}}$ & 93.1 & $96.1^{\mathrm{a}}$ & $52.1^{\mathrm{a}}$ & $52.1^{\mathrm{a}}$ & 33.6 & 37.0 & 7.2 & $5.0^{\mathrm{b}}$ \\
H.TRP & 33.8 & $27.0^{\mathrm{b}}$ & 100.1 & $70.8^{\mathrm{b}}$ & $56.5^{\mathrm{a}}$ & $52.0^{\mathrm{a}}$ & 36.9 & 30.8 & 6.8 & $5.4^{\mathrm{b}}$ \\
SEM & 1.99 & 2.25 & 4.20 & 3.19 & 2.56 & 2.39 & 2.57 & 2.18 & 0.39 & 0.43 \\
$P$ value & 0.94 & 0.001 & 0.19 & 0.02 & 0.02 & 0.01 & 0.89 & 0.56 & 0.93 & 0.003 \\
& & \multicolumn{7}{c}{ TRP vs. control } \\
$P$ value & 0.66 & 0.03 & 0.76 & 0.63 & 0.09 & 0.006 & 0.52 & 0.26 & 0.62 & 0.12 \\
\hline
\end{tabular}

${ }^{\mathrm{a}-\mathrm{b}}$ Mean values in the same column with different superscripts differ significantly $(P<0.05)$.

${ }^{1}$ Five chickens per treatment were used for the determination of plasma TG, TC, HDL-c, LDL-c and VLDL-c.

Table 4 Fatty acids composition of the thigh meat at week 6 of age in broiler chickens receiving 0\% (F.TRP) or $0.25 \%$ (L.TRP), $0.50 \%$ (M.TRP) and $0.75 \%$ (H.TRP) turmeric rhizome powder through the diet

\begin{tabular}{lccccccc}
\hline \multirow{2}{*}{$\begin{array}{l}\text { Fatty acid } \\
(\%)\end{array}$} & ${ }^{1}$ Treatments & & TRP vs. control \\
\cline { 2 - 7 } & F.TRP & L.TRP & M.TRP & H.TRP & SEM & $P$ value & $P$ value \\
\hline C14:0 & 0.61 & 0.60 & 0.60 & 0.59 & 0.02 & 0.99 & 0.87 \\
C14:1n5 & 0.13 & 0.11 & 0.12 & 0.12 & 0.005 & 0.35 & 0.08 \\
C16:0 & 33.40 & 30.98 & 31.07 & 29.79 & 0.54 & 0.11 & 0.02 \\
C16:1n7 & 4.97 & 4.76 & 4.88 & 4.70 & 0.14 & 0.91 & 0.58 \\
C18:0 & 6.39 & 6.44 & 5.96 & 5.95 & 0.15 & 0.51 & 0.43 \\
C18:1n9 & 36.55 & 35.86 & 37.59 & 36.08 & 0.54 & 0.69 & 0.97 \\
C18:1n7 & $1.58^{\mathrm{a}}$ & $1.61^{\mathrm{a}}$ & $1.50^{\mathrm{ab}}$ & $1.24^{\mathrm{b}}$ & 0.05 & 0.046 & 0.24 \\
C18:2n6cis & 14.31 & 14.05 & 14.36 & 15.70 & 0.26 & 0.09 & 0.48 \\
C18:3n3 & 0.71 & 0.69 & 0.71 & 0.78 & 0.03 & 0.71 & 0.80 \\
C18:3n6 & 0.10 & 0.12 & 0.14 & 0.18 & 0.01 & 0.12 & 0.11 \\
C18:4n3 & 0.34 & 0.37 & 0.31 & 0.41 & 0.02 & 0.48 & 0.65 \\
C20:0 & 0.12 & 0.12 & 0.12 & 0.11 & 0.003 & 0.79 & 0.60 \\
C20:4n6 & 0.53 & 0.40 & 0.48 & 0.46 & 0.03 & 0.62 & 0.31 \\
C20:5n3 & 0.17 & 0.18 & 0.20 & 0.20 & 0.007 & 0.40 & 0.24 \\
C22:0 & 0.06 & 0.05 & 0.08 & 0.07 & 0.005 & 0.25 & 0.58 \\
$\sum$ SFA & $40.6^{\mathrm{a}}$ & $38.2^{\text {ab }}$ & $37.8^{\mathrm{ab}}$ & $36.5^{\mathrm{b}}$ & 0.55 & 0.048 & 0.01 \\
$\sum$ UFA & 59.4 & 58.2 & 60.3 & 59.9 & 0.54 & 0.57 & 0.98 \\
UFA/SFA & 1.47 & 1.53 & 1.60 & 1.64 & 0.03 & 0.12 & 0.06 \\
\hline
\end{tabular}

${ }^{a-b}$ Mean values within the same row with different superscripts differ significantly $(P<0.05)$.

${ }^{1}$ Thigh meat of five chickens per treatment was used for the determination of fatty acid composition.

SFA - total saturated fatty acids; UFA - total unsaturated fatty acids; MUFA - total monounsaturated fatty acids;

PUFA - total polyunsaturated fatty acids. 
between the treatments at both ages. Although no significant differences were observed for very low-density lipoproteins-cholesterol between the treatments at week 3, at week 6 the H.TRP- and M.TRP-fed birds had a lower concentration than birds in the other treatments. Furthermore, lower concentrations of plasma triglyceride and higher concentrations of HDL-c were evident with TRP supplementation compared with the control.

Table 4 shows the effect of dietary TRP supplementation on the fatty acid composition of the thigh meat in chickens at week 6 . The H.TRP-fed birds had a lower $(P<0.05)$ total SFA and trans-vaccenic acid (C18:1n7) concentration in thigh meat than the F.TRP-fed birds, but there were no significant differences for these indices between the other birds. Moreover, TRP supplementation reduced the concentrations of palmitic acid $(\mathrm{C} 16: 0)(P=0.02)$ and SFA $(P=0.01)$ in the thigh meat compared with the control. There were no significant differences between treatments in the concentration of the other fatty acids and UFA $(P>0.05)$.

\section{Discussion}

No changes in serum total cholesterol, HDL-c, LDL-c and triglyceride concentrations have been shown in broiler chickens when receiving diets supplemented with $0.1 \%$ or $0.2 \%$ TRP alone or with aloe vera powder (Mehala \& Moorthy, 2008). However, higher plasma HDL-c and lower plasma VLDL-c, triglycerides (by $0.5 \%$ or $1 \%$ dietary TRP supplementation) and total cholesterol (by $1 \%$ dietary TRP supplementation) concentrations were recorded in more recent experiments. Many papers have been published regarding the hypocholesterolemic effects of TRP or its compounds in human and animals. For example, higher serum HDL-c concentrations were observed when $0.25 \%, 0.5 \%$ and $0.75 \%$ TRP were included in broiler chicken diets (Emadi et al., 2007). Dietary supplementation of $0.2 \%$ TRP to laying hens resulted in lower serum triglyceride and total cholesterol concentrations (Kermanshahi \& Riasi, 2006) and the inclusion of $0.1 \%$ or $0.5 \%$ curcumin in rat diets lowered the liver and serum cholesterol concentrations (Rao et al., 1970; Babu \& Srinivasan, 1997). Moreover, dietary supplementation of curcumin decreased the plasma cholesterol, free fatty acids and triglyceride concentrations in female albino rats (Wistar strain) with alcohol induced toxicity (Rukkumani et al., 2003). Kamal-Eldin et al. (2000) reported reduced low plasma density lipoprotein and very low-density lipoprotein and total cholesterol concentrations in the livers of male Sprague-Dawley rats by dietary supplementation of $4 \mathrm{~g}$ curcumin $/ \mathrm{kg}$. Soni \& Kuttan (1992) observed a significant decrease in serum lipid peroxides (33\%), an increase in HDL-c (29\%) and a decrease in total serum cholesterol (12\%) concentrations upon curcumin administration (500 $\mathrm{mg}$ of curcumin per day for $7 \mathrm{~d}$ ) to 10 healthy human volunteers. Furthermore, feeding the turmeric extract along with saturated fats and cholesterol (Ramirez-Tortosa et al., 1999) decreased the plasma cholesterol level and the susceptibility of LDL to oxidation in rabbits. Reduced plasma cholesterol concentrations of TRP-fed birds are possibly related to the altered activity of two effective enzymes in cholesterol metabolism, HMG-CoA reductase and cholesterol 7a-hydroxylase. Although the activity of HMG-CoA reductase was not investigated in the current experiment and in other published studies on TRP, Babu \& Srinivasan (1997) suggested that a cholesterollowering effect of curcumin could be mediated by the stimulation of hepatic cholesterol-7a-hydroxylase activity. Therefore, lower plasma cholesterol concentrations in TRP-fed birds could be related to the stimulating activity of hepatic cholesterol-7a-hydroxylase.

As opposed to total cholesterol and VLDL-c, dietary supplementation of $0.5 \%$ and $1 \%$ TRP depressed the plasma triglyceride concentration in our experiment. This phenomenon may be due to the lowering hepatic lipogenesis effect of TRP, because triglycerides are produced in the liver by hepatic lipogenesis and are secreted into the plasma (Lanza-Jacoby, 1986; Herzberg \& Rogerson, 1988). As a result, decreased hepatic lipogenesis possibly affected the thigh meat triglyceride and saturated fatty acid contents of TRP-fed birds. Neutral lipids (triacylglycerol or triglycerides) of muscle meat are rich in saturated and monounsaturated fatty acids (MUFA) and found in the i.m. adipocytes located in the perimysium (Sanosaka et al., 2008). Adipocyte number and size increase with the total lipid content of the muscle (Mourot \& Hermier, 2001; Wood et al., 2008). The predominant lipids in thigh meat are triglycerides (GonzalezEsquerra \& Leeson, 2000). SFA and MUFA are the results of fatty acid synthesis de novo, whereas polyunsaturated fatty acids originate exclusively from the diet (Lanza-Jacoby, 1986; Herzberg \& Rogerson, 1988). Therefore, a lower percentage of SFA, especially palmitic acid and C18:1 n-7 (a MUFA) in the thigh meat of TRP-fed chickens is the result of decreased de novo synthesis of fatty acids in the liver. Palmitic acid (C16:0) was the main SFA of thigh meat in a recent experiment. The same results have been reported for 
thigh meat of broiler chickens and of steers (Mapiye et al., 2011). Palmitic acid was lower in TRP-fed birds than in the control birds. Along with myristic acid (C14:0), palmitic acid is the responsible fatty acid to raise LDL serum cholesterol (Rowe et al., 1999; Muchenje et al., 2009a; b). Cholesterol can be both good and bad for food consumers. Abnormally high levels of cholesterol and abnormal proportions of low-density lipoproteins (LDL) and high-density lipoproteins (HDL) are associated with cardiovascular diseases (Muchenje et al., 2009a). Studies have demonstrated a strong relationship between LDL cholesterol levels and human cardiovascular diseases and that HDL-c has an inverse relationship with the risk of cardiovascular diseases (Kwiterovich, 1997; Muchenje et al., 2009a). Therefore, a low level of palmitic acid in thigh meat of TRP-fed birds is desirable.

Yasni et al. (1993) observed decreased activity of liver fatty acid synthase, along with decreased serum triglycerides, phospholipids and liver cholesterol concentrations, and increased concentrations of serum HDL-c and apolipoproteins in rats given a cholesterol-free diet by Curcoma xanthorrhiza (Javanese turmeric, a turmeric species). These researchers indicated that Curcoma xanthorrhiza contains an active compound other than the curcuminoids that can modify the metabolism of lipids and lipoproteins and even liver fatty acid synthase activity. In another experiment they identified alpha-curcumene as the major component (approximately 65\%) of Curcoma xanthorrhiza essential oil (Yasni et al., 1994). Addition of $0.02 \%$ Curcoma xanthorrhiza essential oils prepared by steam distillation to a purified diet resulted in a lower hepatic triglyceride concentration in rats, whereas addition of the hexane-soluble fraction $(0.5 \%)$ resulted in a lower concentration of serum, as well as liver triglycerides. Rats fed the essential oil and hexane-soluble fraction had a lower hepatic fatty acid synthase activity. The fraction containing $\alpha$-curcumene suppressed the synthesis of fatty acids from ${ }^{14} \mathrm{C}$-labelled acetate in primary cultured rat hepatocytes. They concluded that $\alpha$-curcumene is one of the active principles exerting triglyceride-lowering activity in Curcoma xanthorrhiza (Yasni et al., 1994). Existence of $6.2 \%$ aromatic curcumene in essential oils of Curcoma longa has been reported by Jayaprakasha et al. (2002). According the results of this experiment showing lower plasma and thigh meat triglycerides concentrations of M.TRP- and H.TRP-fed birds, it seems those aromatic curcumene fractions is possibly the responsible compound of the declining effect of TRP on the fatty acid synthase activity enzyme and consequently lower thigh meat triglycerides and SFAs. Moreover, decreased plasma triglyceride, and thigh meat triglyceride, SFA and vaccenic acid concentrations of TRP-fed birds may be due to a lowering hepatic lipogenesis effect of TRP.

\section{Conclusion}

It was concluded that dietary inclusion of TRP in broiler chickens can increase the crude protein and moisture contents, and decrease the triglycerides and SFAs in thigh meat of broilers and hence improve meat quality.

\section{Acknowledgements}

We sincerely thank the Institute of Biotechnology for financial support of this study.

\section{References}

Aletor, V.A., Eder, K., Becker, K., Paulicks, B.R., Roth, F.X. \& Roth-Maier, D.A., 2003. The effects of conjugated linoleic acids or an $\alpha$-glucosidase inhibitor on tissue lipid concentrations and fatty acid composition of broiler chicks fed a low-protein diet. Poult. Sci. 82, 796-804.

Ammon, H.P.T., Anazodo, M.I., Safayhi, H., Dhawan, B.N. \& Srimal, R.C., 1992. Curcumin: a potent inhibitor of leukotriene B4 formation in rat peritoneal polymorphonuclear neutrophils (PMNL). Planta. Med. 58, 226.

Babu, P.S. \& Srinivasan, K., 1997. Hypolipidemic action of curcumin, the active principle of turmeric in streptozotocin induced diabetic rats. Mol. Cell. Biochem. 166, 169-175.

Blanch, A. \& Grashorn, M.A., 1996. Ernährungsphysiologische Bedeutung der Omega-3 Fettsäuren und Möglichkeiten der Anreicherung in Eiern. Physiological importance of omega-3 fatty acids for human nutrition and ways for their enrichment in eggs. Archiv. fur Geflugelkunde 60, 49-58.

Bolukbasi, Ş.C., Erhan, M.K. \& Özkan, A., 2006. Effect of dietary thyme oil and vitamin E on growth, lipid oxidation, meat fatty acid composition and serum lipoproteins of broilers. S. Afr. J. Anim. Sci. 36, 189-196. 
Bou, R., Guardiola, F., Tres, A., Barroeta, A.C. \& Codony, R., 2004. Effect of dietary fish oil, $\alpha$-tocopheryl acetate, and zinc supplementation on the composition and consumer acceptability of chicken meat. Poult. Sci. 83, 282-292.

Bou, R., Guardiola, F., Barroeta, A.C. \& Codony, R., 2005. Effect of dietary fat sources and zinc and selenium supplements on the composition and consumer acceptability of chicken meat. Poult. Sci. 84, 1129-1140.

Crespo, N. \& Esteve-Garcial, E., 2002. Dietary linseed oil produces lower abdominal fat deposition but higher de novo fatty acid synthesis in broiler chickens. Poult. Sci. 81, 1555-1562.

Daneshyar, M., Kermanshahi, H. \& Golian, A.G., 2007. Changes of blood gases, internal organ weights and performance of broiler chickens with cold-induced ascites. Res. J. Biol. Sci. 2, 729-735.

Daneshyar, M., Kermanshahi, H. \& Golian, A.G., 2009. Changes of biochemical parameters and enzyme activities in broiler chickens with cold-induced ascites. Poult. Sci. 88, 106-110.

Desvilettes, C., Bourdier, G. \& Breton, J.C., 1994. Lipid class and fatty acid composition of planktivorous larval pike (Esox lucius) living in a natural pond. Aquat. Living Resour. 7, 67-77.

Duke, J., 2004. USDA, ARS, National Genetic Resources Program. Phytochemical and ethnobotanical databases. [online database] National Germplasm Resources Laboratory, Beltsville, Maryland, 11 December.

Emadi, M., Kermanshahi, H. \& Maroufyan, E., 2007. Effect of varying levels of turmeric rhizome powder on some blood parameters of broiler chickens fed corn-soybean meal based diets. Int. J. Poult. Sci. 6, 345-348.

Folch, J.M., Less, M. \& Sloane-Stanley, G.H., 1957. A simple method for the isolation and purification of total lipids from animal tissues. J. Biol. Chem. 226, 497-509.

Gonzalez-Esquerra, R. \& Lesson, S., 2000. Effects of menhaden oil and flaxseed in broilers on sensory quality and lipid composition of poultry meat. Br. Poult. Sci. 41, 481-488.

Habibian Dehkordi, S., Zamani Moghadam, A., Maghsoudi, N., Aali, E., Gerami, R. \& DehsadeGhi, E., 2010. The effects of fresh garlic on the serum concentration of total cholesterol, total triglyceride and adipose tissues of broilers. Biochim. Biophys. Acta 19, 363-365.

Hayes, K.C., 1995. Saturated fats and blood lipids: new slant on an old story. Can. J. Cardiol. 11, 39G-46G.

Herzberg, G.R. \& Rogerson, M., 1988. Hepatic fatty acid synthesis and triglyceride secretion in rats fed fructose- or glucose-based diets containing corn oil, tallow or marine oil. J. Nutr. 118, 1061-1067.

Hirose, N., Inoue, T., Nishihara, K., Sugano, M., Akimoto, K., Shimizu, S. \& Yamada, H., 1991. Inhibition of cholesterol absorption and synthesis in rats by sesamin. J. Lipid Res. 32, 629-638.

Ikeda, I., Imasato, Y., Sasaki, E., Nakayama, M., Nagao, H., Takeo, T., Yayabe, F. \& Sugano, M., 1992. Tea catechins decrease micellar solubility and intestinal absorption of cholesterol in rats. Biochim. Biophys. Acta 1127, 141-146.

Jayaprakasha, G.K., Jena, B.S., Negi, P.S. \& Sakariah, K.K., 2002. Evaluation of antioxidant activities and antimutagenicity of turmeric oil: A byproduct from curcumin production. Zeitschrift fur Naturforschung 57, 828-835.

Kamal-Eldin, A., Frank, J., Razdan, A., Tengblad, S., Basu, S. \& Vessby, B., 2000. Effects of dietary phenolic compounds on tocopherol, cholesterol, and fatty acids in rats. Lipids 35, 427-435.

Kermanshahi, H. \& Riasi, A., 2006. Effect of turmeric rhizome powder (Curcuma longa) and soluble NSP degrading enzyme on some blood parameters of laying hens. Int. J. Poult. Sci. 5, 494-498.

Konjufca, V.H., Pesti, G.M. \& Bakalli, R.I., 1997. Modulation of cholesterol levels in broiler meat by dietary garlic and copper. Poult. Sci. 76, 1264-1271.

Kwiterovich, P.O., 1997. The effect of dietary fat, antioxidants, and prooxidants on blood lipids, lipoproteins, and atherosclerosis. J. Am. Diet. Assoc. 97 (Suppl.), 31-41.

Lanza-Jacoby, S., 1986. Effect of continuous and discontinuous intravenous or intragastric total parenteral nutrition in rats on serum lipids, liver lipids and liver lipogenic rates. J. Nutr. 116, 733-741.

Lopez-Ferrer, S., Baucells, M.D., Barroeta, A.C. \& Grashorn, M.A., 1999. N-3 enrichment of chicken meat using fish oil: Alternative substitution with rapeseed and linseed oils. Poult. Sci. 78, 356-365.

Mapiye, C., Chimonyo, M., Dzama, K., Hugo, A., Strydom, P.E. \& Muchenje, V., 2011. Fatty acid composition of beef from Nguni steers supplemented with Acacia karroo leaf-meal. J. Food Compos. Anal. 24, 523-528. 
Mehala, C. \& Moorthy, M., 2008. Effect of Aloe vera and Curcuma longa (turmeric) on carcass characteristics and biochemical parameters of broilers. Int. J. Poult. Sci. 7, 857-861.

Mishra, A., Jaitly, A.K. \& Srivastava, A.K., 2009. Antihyperglycaemic activity of six edible plants in validated animal models of diabetes mellitus. Indian J. Sci. Technol. 2, 80-86.

Mourot, J. \& Hermier, D., 2001. Lipids in monogastric animal meat. Reprod. Nutr. Dev. 41, 109-118.

Muchenje, V., Dzama, K., Chimonyo, M., Strydom, P.E., Hugo, A. \& Raats, J.G., 2009a. Some biochemical aspects pertaining to beef eating quality and consumer health: A review. Food Chem. 112, 279-289.

Muchenje, V., Hugo, A., Dzama, K., Chimonyo, M., Strydom, P.E. \& Raats, J.G., 2009b. Cholesterol levels and fatty acid profiles of beef from three cattle breeds raised on natural pasture. J. Food Compos. Anal. 22, 354-358.

Nishiyama, T., Mae, T., Kishida, H., Tsukagawa, M., Mimaki, Y., Kuroda, M., Sashida, Y., Takahashi, K., Kawada, T., Nakagawa, K. \& Kitahara, M., 2005. Curcuminoids and sesquiterpenoids in Turmeric (Curcuma longa L.) suppress an increase in blood glucose level in type 2 diabetic KK-Ay mice. J. Agric. Food Chem. 53, 959-963.

Piper, J.T., Singhal, S.S., Salameh, M.S., Torman, R.T., Awasthi, Y.C. \& Awasthi, S., 1998. Mechanisms of anticarcinogenic properties of curcumin: The effect of curcumin on glutathione linked detoxification enzymes in rat liver. Int. J. Biochem. Cell Boil. 30, 445-456.

Ponte, P.I.P., Mendes, I., Quaresma, M., Aguiar, M.N.M., Lemos, J.P.C., Ferreira, L.M.A., Soares, M.A.C., Alfaia, C.M., Prates, J.A.M. \& Fontes, C.M.G.A., 2004. Cholesterol levels and sensory characteristics of meat from broiler consuming moderate to high levels of alfalfa. Poult. Sci. 83, 810-814.

Ramirez-Tortosa, M.C., Mesa, M.D., Agullera, M.C., Qulles, J.L., Baro, L. \& Ramirez-Tortosa, C.L., 1999. Oral administration of a turmeric extract inhibits LDL oxidation and has hypocholesterolemic effects in rabbits with experimental atherosclerosis. Atherosclerosis 147, 371-378.

Rao, D.S., Sekhara, N.C., Satyanarayna, M.N. \& Srinivasan, M., 1970. Effect of curcumin on serum and liver cholesterol levels in the rat. J. Nutr. 100, 1307-1315.

Rowe, A., Macedo, F.A.F., Visentainer, J.V., Souza, N.E. \& Matsushita, M., 1999. Muscle composition and fatty acid profile in lambs fattened in drylot or pasture. Meat Sci. 51, 283-288.

Ruby, A.J., Kuttan, G., Babu, K.D., Rajasekharan, K.N. \& Kuttan, R., 1995. Antitumor and antioxidant activity of natural curcuminoids. Cancer Lett. 94, 79-83.

Rukkumani, R., Sribalasubashini, M. \& Menon, V.P., 2003. Protective effects of curcumin and photoirradiated curcumin on circulatory lipids and lipid peroxidation products in alcohol and polyunsaturated fatty acid-induced toxicity. Phytother. Res. 17, 925-929.

Sanosaka, M., Minashima, T., Suzuki, K., Watanabe, K., Ohwada, S., Hagino, A., Rose, M. T., Yamaguchi, T. \& Aso, H., 2008. A combination of octanoate and oleate promotes in vitro differentiation of porcine intramuscular adipocytes. Comp. Biochem. Phys. B, 149, 285-292.

Soni, K.B. \& Kuttan, R., 1992. Effect of oral curcumin administration on serum peroxides and cholesterol levels in human volunteers. Indian J. Physiol. Pharmacol, 36, 273-275.

Staley, L.L. \& Mazier, M.J.P., 1999. Potential explanation for the French paradox. Nutr. Res. 19, 3-15.

Wood, J.V., Enser, M., Fisher, A.V., Nute, G.R., Sheard, P.R., Richardson, R.I., Hughes, S.I. \& Whittington, F.M., 2008. Fat deposition, fatty acid composition and meat quality: A review. Meat Sci. 78, 343-358.

Yasni, S., Imaizumi, K., Nakamura, M., Aimoto, J. \& Sugano, M., 1993. Effects of Curcuma xanthorrhiza Roxb., and curcuminoids on the level of serum and liver lipids, serum apolipoprotein A-I and lipogenic enzymes in rats. Food Chem. Toxicol. 31, 213-218.

Yasni, S., Imaizumi, K., Sin, K., Sugano, M., Nonaka, G. \& Sidik., 1994. Identification of active principle inessential oils and hexane-soluble fractions of Curcuma xanthorrhiza Roxb. showing triglyceride lowering action in rats. Food Chem. Toxicol. 32, 273-278. 